\title{
Fabrication of Micro Compound Tools and Their Application in Drilling
}

\author{
Muhammad Aziz, Osamu OHNISHI, Hiromichi ONIKURA, Nuraslina Sharkawi, Weichen KUO \\ Department of Intelligent Machinery and Systems, Faculty of Engineering, Kyushu University, Japan, \\ aziz@tool-a.mech.kyushu-u.ac.jp
}

\begin{abstract}
:
The research deals with the development of micro compound tool consisting of a micro flat drill as a drilling part and a micro electroplated diamond grinding part for finishing. The study focuses on the fabrication method of these micro compound tools and their application in making and finishing holes into stainless steel (SUS304). From the experiment, it was found that there is an optimum drill point angle which results in a minimum burr formation including entrance and exit burr. Furthermore, ultrasonic vibration during machining could improve the performance of micro compound tool by decreasing the machining force.
\end{abstract}

Keywords: Micro compound tool, Micro flat drill, Electroplated grinding tool, Point angle, USV assisted manufacturing, Burr formation

\section{Introduction}

The fast growing of product miniaturization demands a very precise manufacturing method. In the field of micro machining, hole machining still stands as the most popular machining process for product manufacturing.

There are some methods of micro hole manufacturing such as ion beam machining, laser ablation, EDM, conventional machining, etc. Each of them has its own superiorities upon other and also its limit in machining capability. Conventional machining is chosen in this study because of its practical use, cheaper devising equipment, shorter machining time, and higher precision.

On the other hand, burr formation becomes one of the serious problems in micro machining and also the deburring process in micro machining is a very difficult process to perform. The existence of burr on some manufactured products could cause very critical problems especially the decrease of product quality including its durability and precision.

In this research, conventional drilling becomes the main focus with a further development on the capability of hole finishing after drilling. This is conducted by developing a new grinding part after the drilling part. The objective of this research is developing a new micro tool with a capability of drilling and finishing in one step process to improve the product quality, shorten the manufacturing time and decrease the manufacturing cost. In the current study, the observation is focused on the simple feasibility test of fabricated micro compound tool and also deep observation on drilling part including the burr formation on different drill point angle and influence of ultrasonic vibration.

Stainless steel is used as a workpiece because it is broadly adopted as industrial material brought by its positive characteristics. But, on the other hand, stainless steel has negative characteristics especially on its difficulty to machine because of its low heat conductivity and tendency to work hardening.
With the aim of increasing the performance of the developed micro compound tool, ultrasonic vibration is applied during machining. Zang Deyuan et al. observed that ultrasonic vibration in drilling has the effect of increasing the rigidity of the drill, reducing the extent of drill skidding and increasing the tool life [1].

\section{Experiment Method}

The experiment consists of two continuous processes, fabrication of micro compound tools and their application into through hole machining. Furthermore, the former is divided into a machining of a drill-substrate and electroplating of machined drill-substrate. Basically, all the experiments are conducted on a vertical type machining center except for the electroplating process.

\subsection{Drill and substrate machining}

A diamond grinding wheel is clamped on the main spindle having an axis in the $Z$ direction. On the other hand, the tool blank, as a workpiece, is clamped on the sub-spindle fixed on the rotary table, which is, in turn, mounted on the $X Y$ table of the machining center. Before grinding, truing and dressing of the grinding wheel are conducted for its end and side faces by a GC rotary dresser having a grit number of 3000 .

With the consideration of material stiffness, grinding is performed in order of the flank, peripheral and flute surfaces. In the case of flank surface grinding, the tool blank is ground under the condition that the round table is rotated by an angle corresponding to the point angle. After finishing the first flank surface, the tool blank is revolved by $180^{\circ}$ and another flank surface is ground. For the peripheral surface, the tool blank is ground by feeding the grinding wheel linearly in the $-Z$ direction including the machining for drilling and grinding parts. For the flute surface, the fixed tool blank is rotated according to the decided chisel edge and then it is ground by feeding the grinding wheel linearly in the $-Z$ direction with inclination 
corresponding to the web taper. After finishing the first flute surface, tool blank is rotated by $180^{\circ}$ and another flute surface is ground.

Three different drill point angles are created by giving different rotation angles for the rotary table during flank surface grinding. Diamond grinding wheel is SD3000I100M with four slits at its end face. The tool blank is made of ultra-fine grained cemented carbide having a WC particle diameter of $90 \mathrm{~nm}$. Figure 1 and Table 1 show the design of the micro compound tool and detail of grinding conditions respectively.

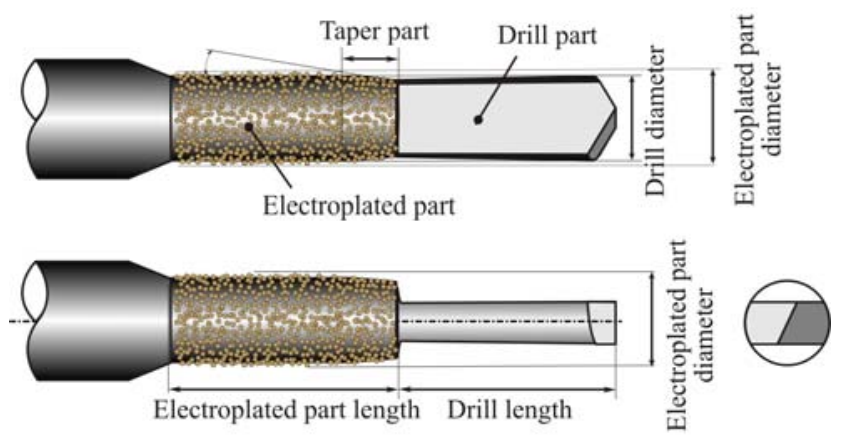

Figure 1: Design of micro compound tool

Table 1: Grinding conditions

\begin{tabular}{|c|c|c|}
\hline Grinding wheel & \multicolumn{2}{|l|}{$\begin{array}{l}\text { SD3000I100M } \\
\text { Diameter } 12 \mathrm{~mm}\end{array}$} \\
\hline Work piece & $\begin{array}{l}\text { Material : ultra fine } \\
\text { carbide } \\
\text { Initial diameter } 1.05 \\
\text { Desired drill geome } \\
\text { Diameter } \\
\text { Flute length } \\
\text { Point angle } \\
\text { Clearance angle } \\
\text { Chisel edge angle } \\
\text { Back taper } \\
\text { Grinding part geom } \\
\text { Substrate diameter } \\
\text { Substrate length } \\
\text { Entrance taper }\end{array}$ & $\begin{array}{l}\text { nented } \\
\text { m } \\
90 \mu \mathrm{m} \\
300 \mu \mathrm{m} \\
100^{\circ}-130^{\circ} \\
16^{\circ} \\
115^{\circ} \\
5 / 100 \\
90 \mu \mathrm{m} \\
300 \mu \mathrm{m} \\
10 / 100\end{array}$ \\
\hline $\begin{array}{l}\text { Grinding cond. } \\
\text { Rotation speed } \\
\text { Feed speed } \\
\text { Coolant } \\
\text { Dresser }\end{array}$ & $\begin{array}{l}4200 \mathrm{~min}^{-1} \\
100 \mu \mathrm{m} / \mathrm{min} \text { : flank } \\
50 \mu \mathrm{m} / \mathrm{min} \text { : flute } \\
\text { Water based coolant } \\
\text { GC3000 }\end{array}$ & periphery \\
\hline
\end{tabular}

\subsection{Electroplating}

Electroplating process consists of some continuous processes including cleaning of the substrate, masking, strike plating by nickel for $2 \mathrm{~min}$, electroplating of diamond grits and embedding them into the electroplated layer. The cleaning of substrate is conducted firstly by acetone with ultrasonic vibration before masking, secondly by cathode electrolytic degreasing at $60{ }^{\circ} \mathrm{C}$ with a current density of $8.5 \mathrm{~A} / \mathrm{dm}^{2}$ and a time of $5 \mathrm{~min}$ and thirdly by submergence in sulfuric acid diluted by 10 times. Between the cleaning processes, the washing in the distilled water is conducted. Masking for the drilling part and the shank above the grinding part is conducted after the first and before the second cleanings by the use of masking liquid and tape respectively. Ni-W electroplating is performed in the ammonia citrate bath with a current density of $2.0 \mathrm{~A} / \mathrm{dm}^{2}$, a temperature of $60^{\circ} \mathrm{C}$, a pH 6.5 and an electroplating time of $15 \mathrm{~min}$. Figure 2 shows the detail of electroplating devices. Diamond grits with diameter of 2-4 $\mu \mathrm{m}$ are electroplated on the grinding part having diameter of $90 \mu \mathrm{m}$ and length of $300 \mu \mathrm{m}$. The automatic intermittent stirring method by a syringe is performed in order to get a uniform grit distribution. Detail of electroplating conditions is shown in Table 2.

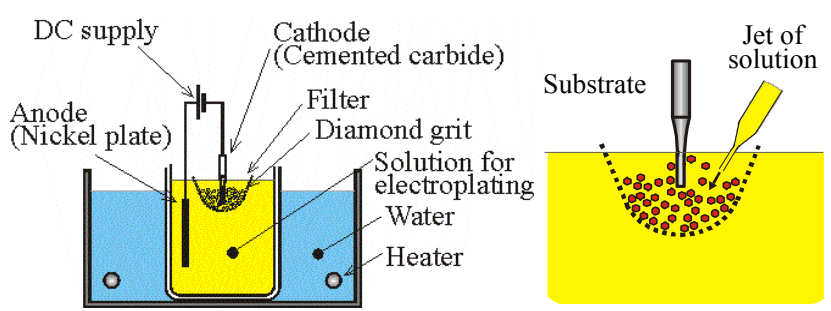

(a) Electroplating bath

(b) Stirring of solution Figure 2: Electroplating devices

Table 2: Electroplating conditions

\begin{tabular}{|l|l|}
\hline Bath & $\begin{array}{l}\text { Ammonia citrate bath } \\
\mathrm{Ni}\left(\mathrm{SO}_{3}\right)_{2} \cdot 4 \mathrm{H}_{2} \mathrm{O}, \\
\left(\mathrm{NH}_{4}\right)_{10} \mathrm{~W}_{12} \mathrm{O}_{41} \cdot 5 \mathrm{H}_{2} \mathrm{O}, \\
\mathrm{C}_{6} \mathrm{H}_{5} \mathrm{O}_{7}(\mathrm{COOH})_{3}\end{array}$ \\
\hline Strike plating liquid & $\begin{array}{l}\text { Sulfuric acid } \mathrm{H}_{2} \mathrm{SO}_{4} \text { and nickel } \\
\text { sulfate } \mathrm{NiSO}_{4}\end{array}$ \\
\hline Strike plating time & $2 \mathrm{~min}$ \\
\hline Grit diameter & $2-4 \mu \mathrm{m}$ \\
\hline Stirring method & Automatic intermittent stirring \\
\hline Electroplating density & $2 \mathrm{~A} / \mathrm{dm}^{2}$ \\
\hline Electroplating time & $15 \mathrm{~min}$ \\
\hline Embedding time & $2 \mathrm{~min}$ \\
\hline
\end{tabular}

\subsection{Hole machining}

In this research, shim tape-liked SUS304 is selected as the workpiece. To provide a high rotation speed, a motor spindle, ASTRO-E500Z Nakanishi Inc., is fixed on the $Z$ axis of machining center instead of BT shank used for drill and substrate machining. In order to maintain the experiment condition to be the same, the radial run out at the $3 \mathrm{~mm}$ point measured from the drill top is $1-2 \mu \mathrm{m}$. The detail of drilling conditions is shown in Table 3.

In drilling without ultrasonic vibration, the workpiece is clamped on the jig having some pilot holes and it is installed on the $X Y$ table of machining center. On the other hand, in the case of drilling with ultrasonic vibration, workpiece is clamped on the ultrasonic vibration table having a natural frequency and double amplitude of about $63.5 \mathrm{kHz}$ and $1.5 \mu \mathrm{m}$ respectively.

Firstly, the study is focused on a simple feasibility test of fabricated micro compound tools regarding their capabilities to improve the hole quality including the ability to decrease the burr size and smooth the hole-wall 
surface. For this purpose, drilling of 20 holes is conducted under the condition of ultrasonic vibration assistance.

Secondly, for a deeper observation, the study is focused on the drilling part regarding the influence of drill point angle, etc. With the purpose of observing the growth of wear and burrs, including entrance and exit burrs, the drilling process is stopped for every 100 holes of machining. Tool wear and workpiece burr are observed using scanning electron microscope. The maximal limit of burr width for both holes entrance and exit are set to $5 \mu \mathrm{m}$ considering that the finishing diameter of the hole is 100 $\mu \mathrm{m}$ and the diameter of drill is $90 \mu \mathrm{m}$.

Table 3: Drilling conditions

\begin{tabular}{|l|l|}
\hline Drill blank & Cemented carbide \\
\hline Work piece & SUS304 \\
\hline Ultrasonic vibration & Without, With \\
\hline Drilling conditions & \\
Drilling depth & $100 \mu \mathrm{m}$ \\
Hole diameter & $90 \mu \mathrm{m}$ for drilling \\
& $100 \mu \mathrm{m}$ for finishing \\
Rotational speed & $10,000,30,000$ min $^{-1}$ \\
Feed speed & $0.5,1.5 \mathrm{~mm} / \mathrm{min}$ \\
Coolant & Water based coolant \\
\hline
\end{tabular}

\section{Experiment Results}

\subsection{Fabricated compound tool}

Figure 3 shows the fabricated micro compound tool. As it is described above that micro compound tool consists of two main parts, drill and electroplated parts. The diameters of the drill top and grinding part are $90 \mu \mathrm{m}$ and $100 \mu \mathrm{m}$ respectively. The drill itself has a back taper enhancing its capability on chip removal. There is a taper also on the entrance of electroplated part after the end of drill back taper with the aim of increasing the cutting efficiency and also avoiding a premature peeling of the electroplating layer.

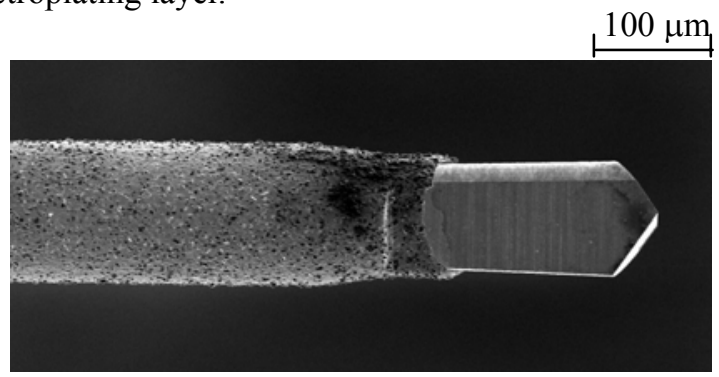

Figure 3: Fabricated micro compound tool

\subsection{Simple feasibility test}

Before going to a deeper study of micro compound tool, a simple feasibility test is conducted in order to know the performance and problems laid on the developed micro compound tool. It is conducted by machining of 20 holes comparing between drilling with and without finishing by developed micro compound tool and micro flat drill respectively. Figure 4 shows the result of this observation. As it could be observed, holes machined by micro compound tool have smaller burr size and smoother hole-wall surface. From this result, the current problems of developed micro compound tool are also clarified. Although the burr size and wall surface is getting better, there still exists a burr which should be removed to get a more burr-free of hole. For this purpose, a deeper study on burr formation is conducted including burr formation during drilling and burr removal during grinding process.

\subsection{Ultrasonic vibration assisted machining}

With a purpose of increasing the performance of micro compound tool, the application of ultrasonic vibration during machining is observed. Figure 5 shows the burr condition of machined holes after drilling of 100 holes under conditions of with and without ultrasonic vibration. At the hole entrance, burrs under both conditions are seems equal in size but it is significantly different at the hole exit. The details of burr condition, including burr width and height, are shown in Fig. 6.

For both conditions, as the number of holes is increasing, burr width and height are also gradually getting larger. But unfortunately, machining without ultrasonic vibration brings a very progressive increase of burr width and height.

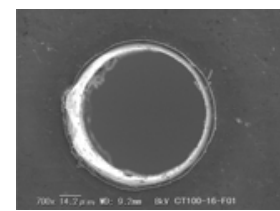

$1^{\text {st }}$ hole

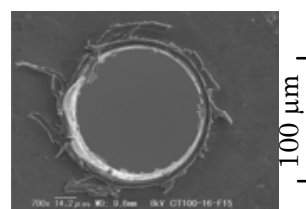

$20^{\text {th }}$ hole

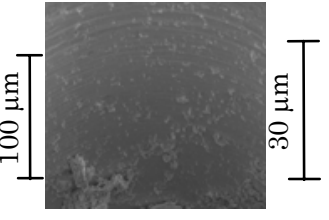

Wall surface (a) Drilled by micro flat drill

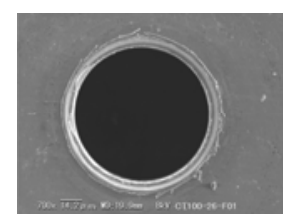

$1^{\text {st }}$ hole

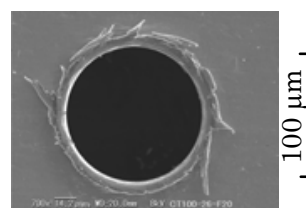

$20^{\text {th }}$ hole

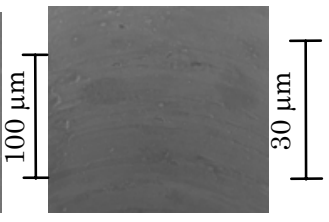

Wall surface (b) Drilled by compound tool

Figure 4: Hole entrance and wall surface in simple feasibility test at hole entrance (USV, $118^{\circ}, 30,000 \mathrm{~min}^{-1}, 1.5 \mathrm{~mm} / \mathrm{min}$ )

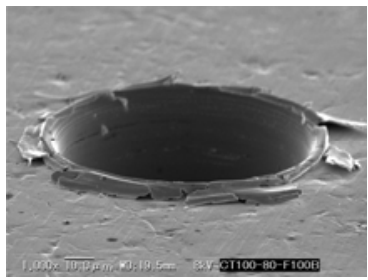

(a) Entrance, with USV

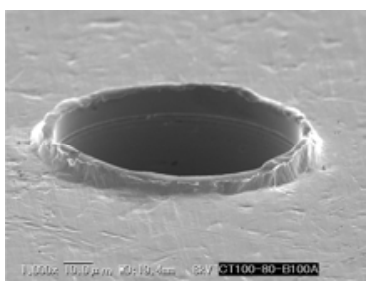

(c) Exit, with USV

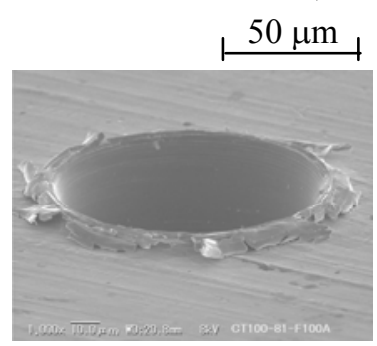

(b) Entrance, without USV

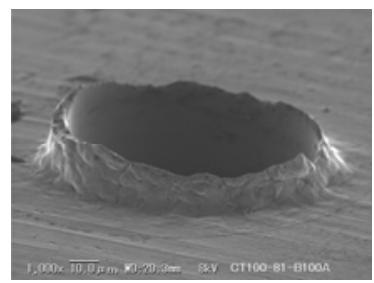

(d) Exit, without USV
Figure 5: Burr size comparison in drilling with and without USV at $100^{\text {th }}$ hole $\left(118^{\circ}, \quad 30,000 \mathrm{~min}^{-1}, 1.5 \mathrm{~mm} / \mathrm{min}\right)$ 


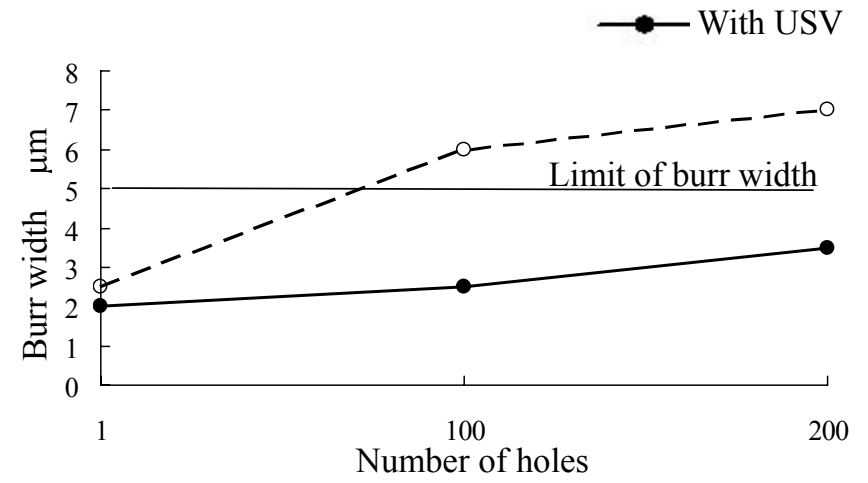

(a) Burr width at hole exit (b) Burr height at hole exit

Figure 6: Burr comparison between drilling with and without USV (118 $\left., 30,000 \mathrm{~min}^{-1}, 1.5 \mathrm{~mm} / \mathrm{min}\right)$

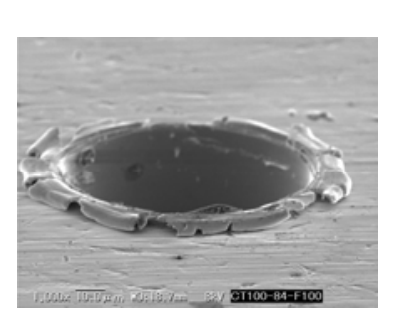

Entrance burr

(a) Drill point angle of $100^{\circ}$

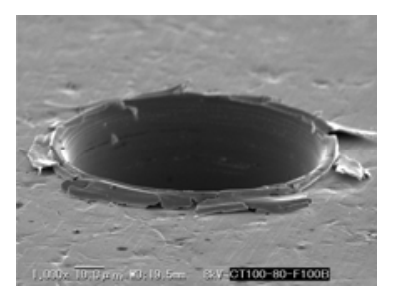

Entrance burr

(b) Drill point angle of $118^{\circ}$

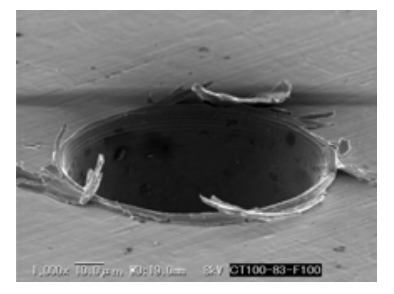

Entrance burr

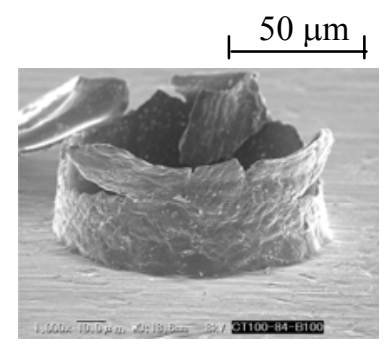

Exit burr

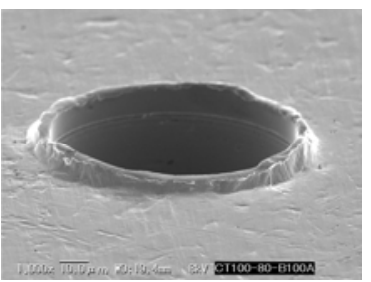

Exit burr

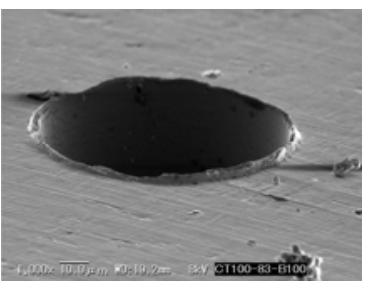

Exit burr

(c) Drill point angle of $130^{\circ}$

Figure 7: Burr formation at $100^{\text {th }}$ hole

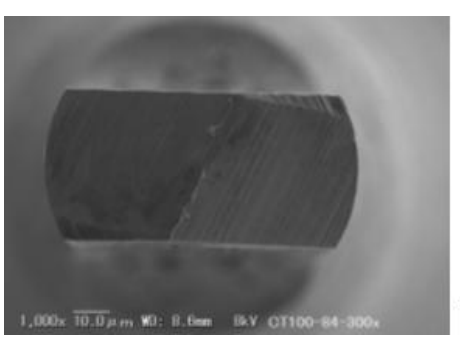

(a) Point angle of $100^{\circ}$

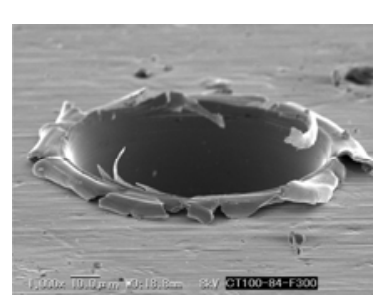

Entrance burr

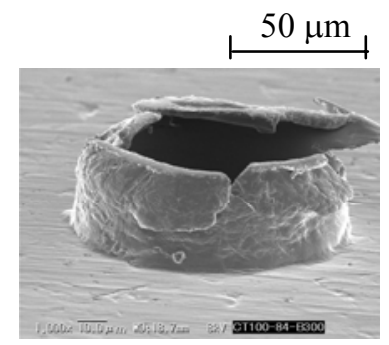

Exit burr

(a) Drill point angle of $100^{\circ}$

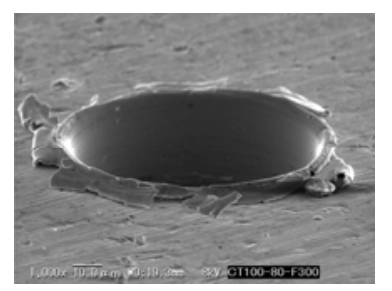

Entrance burr

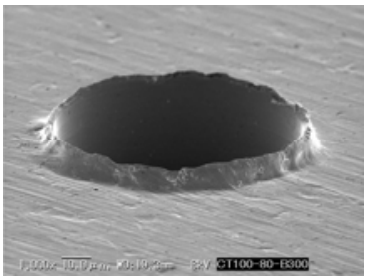

Exit burr

(b) Drill point angle of $118^{\circ}$

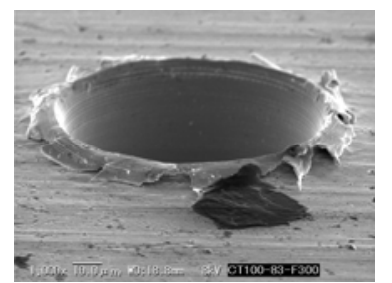

Entrance burr

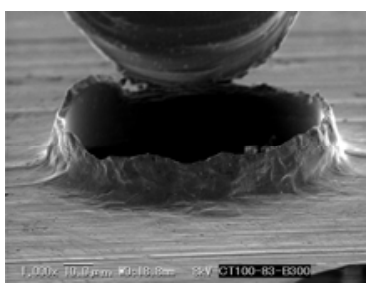

Exit burr

(c) Drill point angle of $130^{\circ}$

Figure 8: Burr formation at $300^{\text {th }}$ hole

Figure 9: Tool wear comparison with different drill point angle after drilling of 300 holes 


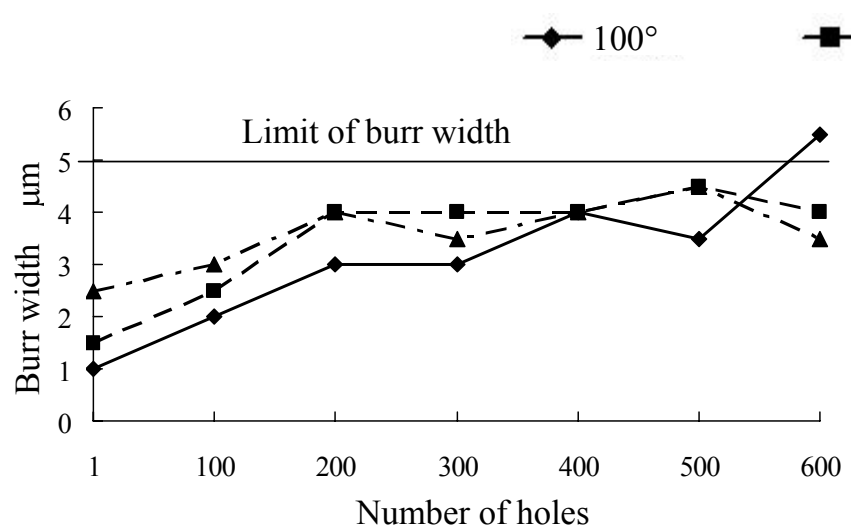

(a) Burr width at hole entrance

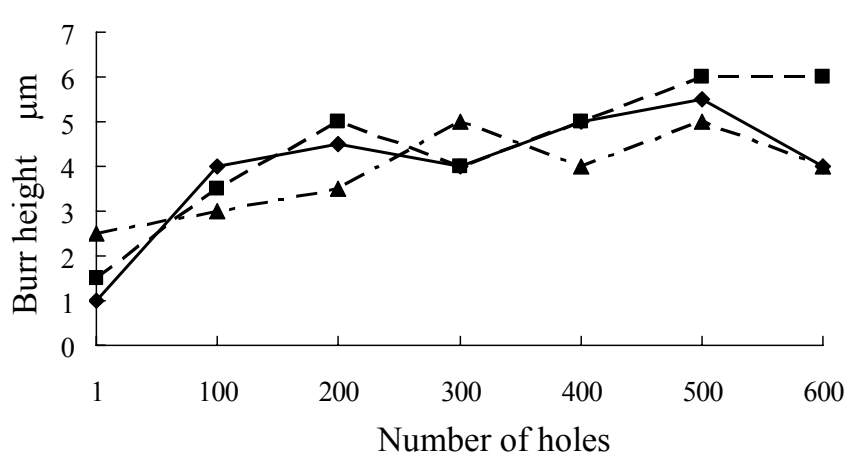

(c) Burr height at hole entrance $118^{\circ} \quad \mathbf{-} 130^{\circ}$

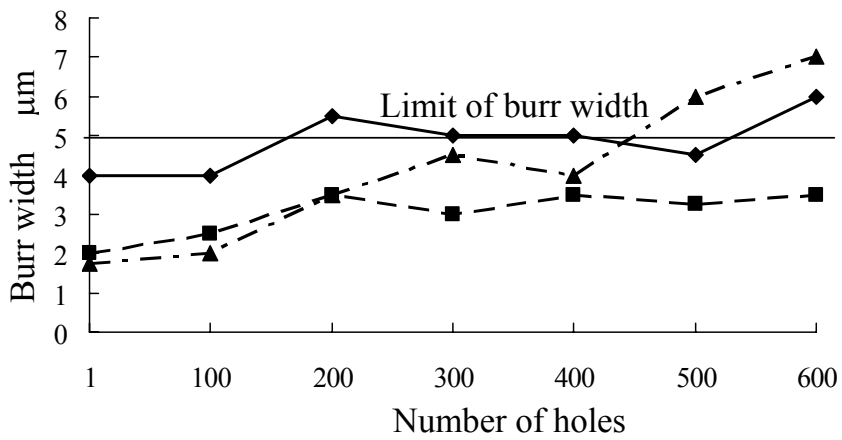

(b) Burr width at hole exit

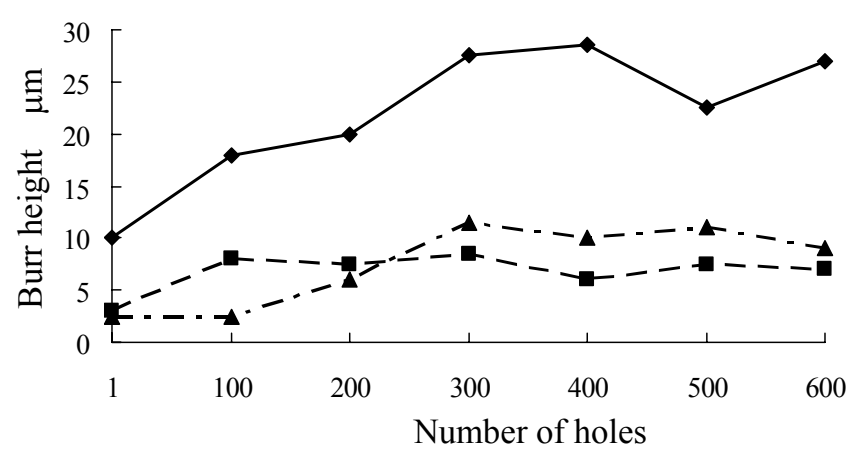

(d) Burr height at hole exit

Figure 10: Burr measurement for different drill point angle $\left(30,000 \mathrm{~min}^{-1}, 1.5 \mathrm{~mm} / \mathrm{min}, \mathrm{USV}\right)$

\subsection{Comparison of drill point angle}

Tools with three different drill point angles are tested in respect of observing the formed burrs and finding the most optimal drill shape suitable for the micro compound tool. They are drill point angle of $100^{\circ}, 118^{\circ}$ and $130^{\circ}$. Figures 7 and 8 show the formed burrs after machining of 100 and 300 holes correspondingly. The detail growths of burr width and height for each different drill point angle are shown in Fig. 10. There is no significant change in entrance burr for both burr width and height although the number of hole is increasing. Conversely, at the hole exit, they showed a very significant difference between them. Point angle of $100^{\circ}$ produced the largest burr width and height compared with other two point angles. On the other hand, point angle of $118^{\circ}$ formed a stagnant growth of burr width and height even the number of hole is progressing. Finally, point angle of $130^{\circ}$ resulted in moderate changes of burr width and height. Under drilling of 200 holes, drill point angle of $130^{\circ}$ could produce a smaller burr formation compared with the point angle of $118^{\circ}$ although, contrarily, it was getting larger after machining of 300 holes.

Figure 9 shows the comparison of tool wear with different drill point angles after drilling of 300 holes under condition of ultrasonic vibration assistance. It could be observed clearly that the tool wear is growing faster as the drill point angle is getting larger.

\section{Discussion}

\subsection{Effect of ultrasonic vibration}

Ultrasonic vibration applied during machining brings an effect of lubrication that reduces the cutting force as it has been studied by Y.J. Liu, et al [2]. The decrease of cutting force, especially the thrust force, of micro flat drill also has been clarified before in previous study, whereas the thrust force decreased to one fifth by applying the ultrasonic vibration during drilling [3]. On the other hand, the additional oscillation inside the drill causes a sawing tooth-like trajectory at the drill top (cutting edges). Thus, drilling supported by ultrasonic vibration can also be seen as drilling procedure overlapped with oscillations by making use of high frequency oscillation [4].

As it is shown in Fig.5, when the ultrasonic vibration is applied during machining, burr produced throughout drilling has a smaller width and height compared when no ultrasonic vibration is applied. From this result, it is considered that the ultrasonic vibration could reduce the extrusion force resulted on the drill top then it decreased the size of burr, especially the exit burr, including the burr width and height. Also, it is assumed that assigning ultrasonic vibration could advance the chip removal capability of the tool. Hence, ultrasonic vibration could improve the cutting efficiency and also diminish the plastic deformation, especially in machining of stainless steel as it has a high tendency to plastic deformation. 


\subsection{Effect of drill point angle on burr formation}

Burr is formed continuously throughout the drilling process started from the entrance to the exit stage. The burr is pushed out in the circumferential direction and its size depends on the sharpness of the cutting edges, point angle and chisel edge of the drill.

At the entrance stage, burr is formed immediately after the corner of the cutting edges firstly hit the workpiece. Chips in drilling are mainly formed by two sides of cutting edges. The rake angle of chisel edge in the micro flat drill is always negative. As the drill point angle is getting larger, the rake angle of chisel edge is getting largely negative which causes an increase of cutting resistance during machining and vice versa.

On the other hand, Sung-Lim Ko, et al, studied that a larger point angle could reduce the burr size and produce a shorter broken chips [5]. But unfortunately, because as a larger point angle produces a larger cutting resistance, a drill with a larger point angle will suffer heavier causing a faster growth of the tool wear. Based on this consideration, it is understood that tool with point angle of $130^{\circ}$ could form a smaller burr size at initial 200 holes than the other point angles but it is getting significantly increase after it. For the new fabricated tool, cutting process is performed mainly by a shearing force distributed along the two cutting edges. But, when the tool is getting dull, the cutting process is conducted mainly by friction force transferred from the tool to the workpiece.

At the exit stage, when the tool tip reaches the critical exit stage, the amount of plastic deformation is increasing. Tool with a smaller point angle will have a concentrated tensile strain at the center of the hole exit rather than it is distributed throughout the hole exit. Otherwise, tool with a larger point angle has a tensile strain distributed throughout the hole exit rather than it is concentrated at the drill tip.

Tool with a smaller point angle will reach a critical exit stage faster than the larger one. Afterwards, the workpiece is broken and the strain at the exit layer significantly decreases. As the strain is losing, the burr formation is mainly driven by a plastic deformation rather than by an effective cutting. In this research, it is understandable that the tool having point angle of $100^{\circ}$ formed the largest burr size at the hole exit.

\section{Conclusion}

Micro compound tools could be fabricated well by associating the fabrication method of micro flat drill and electroplating. From the simple feasibility test, it is clear that the new developed tools could improve the hole quality by decreasing the size of burrs, both entrance and exit burrs, and smoothing the hole surface.

Ultrasonic vibration applied in machining of SUS304 using the fabricated micro compound tool indicatively promoted a better result of machining by reducing the plastic deformation and advancing the performance of the tool during machining. Burr formation could be restrained and the tool life is getting longer as the machining force was dropping off.
Tool with a point angle of $118^{\circ}$ is considered as the best one because it could form burrs in smaller size stagnantly and still showed a moderate tool wear even drilling of 600 holes. Tool with a point angle of $100^{\circ}$ has a smallest cutting resistance but it causes a faster plastic deformation at the exit stage resulting a large exit burr from a very initial hole machining. On the other hand, tool with a point angle of $130^{\circ}$ shows a good performance at initial 200 holes but it is getting worse as the tool wear is growing rapidly.

\section{Acknowledgement}

The author would like to acknowledge to Mr. Takao SAJIMA and Mr. Sho TSURUOKA for their warm cooperation and support during this research work.

\section{References}

[1] Zhang Deyuan, et al, 1998, Investigation of Chip in Vibration Drilling, International Journal of Machine Tools and Manufacturing, Vol.38, No.3, pp. 165-176,

[2] Y.J. Liu, T. Inamura, N. Takezawa, 2006, Effects and Possible Role of Atmospheric Molecules in Ultra-micro-cutting of Monocrystalline Silicon, Journal of Precision Engineering, Vol.30, pp231-237.

[3] Muhammad Aziz, et al., 2006, The Performance of Micro Long Flat Drill with a Diameter of $20 \mu \mathrm{m}$ in Drilling into Duralumin and Stainless Steel, Proc. of the $8^{\text {th }}$ International Conference on Progress of Machining Technology, pp.373-376.

[4] Reimund Neugebauer, Andrea Stoll, 2003, Ultrasonic Application in Drilling, Journal of Materials Processing Technology, Vol.149, pp.633-639.

[5] Sung-Lim Ko, et al, 2001, Analysis of burr formation in drilling with a new concept drill, Journal of Materials Processing Technology, Vol.113, pp.392-398. 